\title{
SOME EVIDENCES OF THE IMPORTANCE OF THE DENTAL PATH AS A SOURCE OF SERIOUS LOCALIZED AND GENERAL INFECTIONS. ${ }^{1}$
}

\author{
By Thomas B. Hartzell, D. M. D., M. D., Research Professor of Mouth Infections, \\ Medical School, and Professor of Oral Surgery and Clinical \\ Pathology, College of Dentistry, University of Minnesota.
}

$I^{\prime}$ T IS a great privilege to address you this evening on the occasion of the dedication of this building to the uses of the Research Institute of the National Dental Association. The challenge of Doctor Mayo, given us three years ago in Chicago to add our share as a profession to the great work being done in preventive medicine, has been accepted by us in good faith, and it is indeed a happy event and a matter for congratulation that we enjoy his counsel and assistance in guiding the work of the Research Institute so splendidly initiated and carried forward by the untiring efforts of our chairman, Doctor Price.

It has been an inspiration to listen to the wonderful address of Doctor Mayo this evening, and I am sure that the various workers in the research field of the National Dental Association will attack their problems with renewed vigor and intensified interest as a result of the words of inspiration uttered by him. Never has there been a time in the history of medicine and dentistry when these two professions have been in such perfect accord, and we, as a dental profession, have cause to be grateful that these great leaders in the constructive

${ }^{\top}$ Read at the dedication of the Research Institute of the National Dental Association, Cleveland. Ohio. work of medicine and surgery, Doctors Mayo and Crile, are members of our administrative body, giving their time and effort to aid us in the task which we have undertaken.

I have believed for many years that some of our methods of practice in dentistry have been responsible for the loss of human life, because we have fostered conditions in practice which have led to the introduction of needless infection into the circulation of patients under our care and my part of the research has been to gather proof to fix the responsibility for the introduction of such infections upon our own shoulders, and at the same time to point out methods of preventing them. I shall take the liberty of discussing only those types of infection which are most com. mon, not attempting to deal either with the rare infections or those now well understood, of which latter diphtheria is an example. It is indeed true that the mouth, by reason of its size and function, is probably the host at one time or another of almost every type of bacterial growth. The great majority of these growths, however, are visitors and not permanent inhabitants. It is the permanent inhabitants that are found in all mouths which interest us most, and, of these permanent inhabitants, there is 
not one possessing such varied possibilities for disease as the streptococcus group and to it we will devote most of our attention. I wish to state clearly in the beginning that in discussing the varied activities of the streptococci, I am well aware that I am not bringing new material regarding the activity of this organism. We all know that most of the lesions in different parts of the body produced by the streptococci have been studied in detail by many obseryers. I do wish, however, to make the point that while Rosenow, Klotz, Poynton and Payne, and many others have worked with the streptococcus, they have wrought without particular reference to the dental avenues of infection, and it was not until the work of Goadby, published in 1912 in the rheumatism number of the London Practitioner, that particular reference to the tooth avenue of infection received systemic or detail ed study in the years 1910, 1911, and 1912 carried on a series of studies by which he was able to produce experimental rheumatism in rabbits, and, by the elimination of primary foci in the dental tract and the use of vaccines to supplement elimination, he was able to secure the recovery of three severe cases of arthritis deformans. To him, therefore, I think must be given the credit for publishing the first observations on the relation of dental infection to that form of rheumatism.

If there be anything of marked value in this paper which may be of future use, it will be in the fact that it offers definite and positive proof that the socalled dental path of infection hitherto little appreciated is shown to be important and that organisms taken from the dental path have produced in animals almost all of the forms of lesion hitherto described; to wit, lesions of the heart-muscle and endocardium, lesions of the kidney, focal and diffuse, lesions of the adventitia of the bloodvessels, and lesions of joints and mus- cles. The evidence of Poynton and Payne (1) gained by creating an experimental iritis in the eye of a rabbit by introducing streptococci in the circulation of the animal, together with the positive clinical results gained by the treatment of our twenty cases of iritis, enables us to place iritis in this category also.

Before proceeding to further discussion of infections, I wish to speak of the dental tract itself. We have in the dental tract the masticating mechanism originating in the epithelium of the mucous membrane, budding and projecting from it into the tissues to later become inclosed by bony walls which grow and finally almost envelope it. Its direction of growth in the first instance is downward and into the tissues, the tooth later bursting the very mucous membrane from which it originated (Figs. 1, 2, 3). The mucous membrane is designed to protect the tissues, blood stream, and lymphatics from infection. The union of the mucous membrane to tooth structure is always, after the eruption of a tooth, imperfect and capable of admitting infection. It is a notable fact that the dental structure has no protecting device, save its coat of enamel. If this be in any way imperfect there seems to be no anti-bodies or protecting leucocytes in the saliva to save it from the disintegrating effect of bacterial action. Unless aid be given by thoro cleansing of tooth surfaces, the integrity of the tooth is sooner or later destroyed by acid-forming micro-organisms which make its surface their home and later enter into its structure. How great a site for bacteria the tooth surface is can only be appreciated by the use of some method of staining bacterial masses in situ. If in the study of mouth infections, particularly those about the teeth, the observer will use a disclosing solution as recommended by skinner, freely applied to the tooth's surface, he will bring to view macroscopically, masses of liv- 

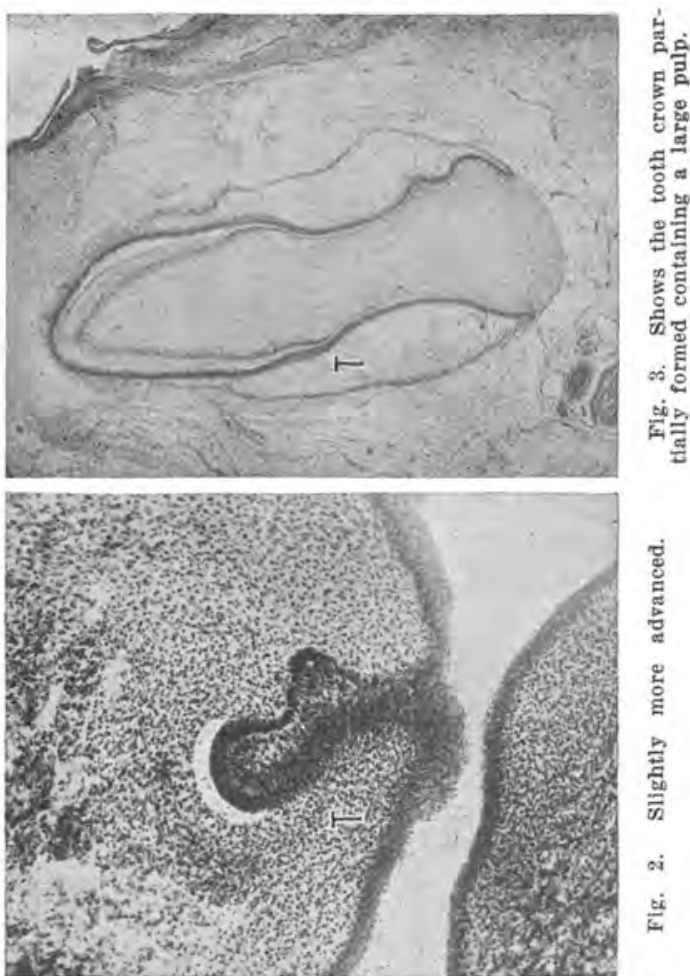
巳ृ 홍
密

का

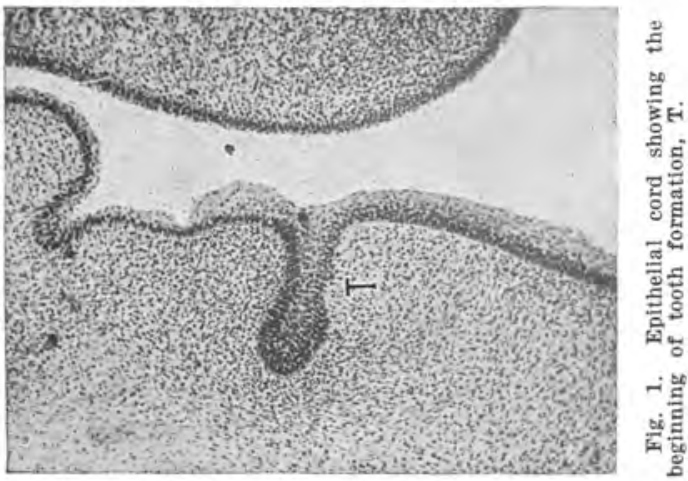


ing bacteria, which Kligler (2) has shown to contain twenty, to six hundre 1 million to the milligramme (Fig. 4). These will be found on cultural and microscopic examination to count among their numbers, the streptococcus, the various staphylococci, the pneumococcus, the spirochæte macrodentium and microdentium generally, and always the fusiform bacillus. In addition to these already mentioned are two protozoa, the entamceba buccalis and the trichomonas showing as well the lack of mucousmembrane protection at the gingival crevice. It will be seen by a study of these pictures that motile organisms growing on the tooth's surface or organisms which reproduce rapidly may readily pass into the delicate openings in the bottom of this crevice, thus gaining direct access to venules and perivascular lymph-spaces in these structures, with nothing to hinder their transfer to the deeper tissues by the lmyph and blood

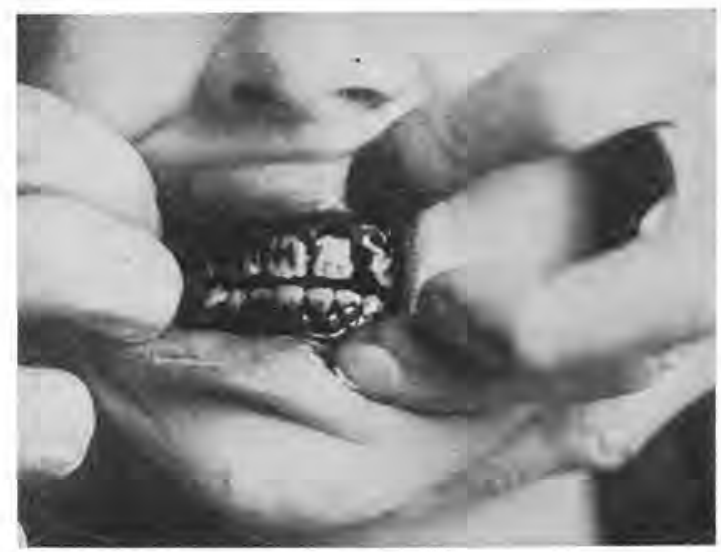

Fig. 4. Showing bacteria stain in mass on the teeth of a chtld. These teeth without discoloring stain are white.

intestinalis. It will be seen from a study of the flora of the tooth surface that this flora always has the power to infect the soft tissues about it. Next we will show the capability of the structures about the tooth to receive infection from it.

Our next point of interest, therefore, is the gingival crevice or gum marginal crevice, in total length about thirty inches, protected externally by a tough pavement epithelium, but containing almost no epithelial protection (Fig. 5) at its point of union with the tooth structure. This lack of protection is well illustrated by recent preparations of Henrici, originally made to demonstrate the vascularity of (Fig. 6) the tissues immediately surrounding the teeth but streams. This process is in the majority of individuals greatly aided by the formation of calculus (Fig 7) on the root surface or at the gingival margin. When once an organism enters the tissue at this point its future progress into the tissues is hastened by the vast power of mastication, the sum of masticatory pressures amounting to about one ton per day in the average individual. The masticatory force depresses the tooth in its joint or socket and the elasticity of the tissues causes rebound when the power of occlusion is released. The tooth, therefore, plays the part of a piston during mastication with the average movement of a sixtieth of an inch. It cannot be doubted that this movement 
aids the ingress of organisms to the underlying tissues thru the unprotected areas of the gum crevice. The masses of bacteria growing on the tooth's surface and in the gingival crevice, even if they do not always gain access to the tissues in the way just described, produce enzymes and irritating toxins, which inflame the gum margin, resulting in œdema and further favoring bacterial development in this thin wedge of tissue. This brings about as a rule destruction of the few cells lining the crevice, causing ulceration (Fig. 8), paving a way fore, that we have abscess in the tissues about living teeth as well as about dead or pulpless teeth, because the conditions favor the planting of infection in this locality. It may be that a dead tooth provides a locus minoris resistentiæ (3) in its neighborhood, but to accept this as a principle governing the formation of abscess about all dead teeth, or even in the majority of instances, I regard as premature and likely to lead to a wrong attitude on the part of dentists and physicians concerning a very vital subject.

In the stidy of a series of acute dental

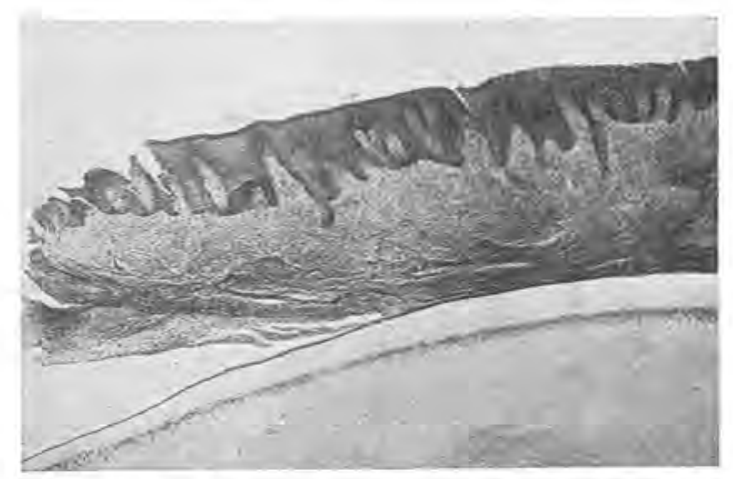

Fig. 5. Normal human gum, showing bottom of a ererice poorly protected by epithelium.

presently to pyorrhœa and providing the potential for peridental inflammations such as abscess, etc. The writer has record of one hundred and fifty teeth which were absolutely sound as far as the enamel was concerned, the pulps of which had been destroyed by infection, and we quite often find teeth, the pulps of which are undergoing profound inflammation without having been exposed by decay. The most plausible explanation for this is, that this richly vascular tissue surrounding the tooth has received infective organisms from the tooth's surface which have been conveyed thru the vessels to the pulp, as we have been able in many instances to obtain micro-organisms in these newly opened pulp chambers. It is not surprising, there- abscesses during the past year we find the staphylococcus the active organism, while in the study of material taken from 250 chronic abscesses of the cystic or granulomatus type, the streptococcus viridans is found to be the predominating organism. All teeth whose pulps have become exposed thru the medium of caries are infected and mastication into the pulp chambers of such teeth insures infection of the para-apical tissue. Teeth which are heavily coated with bacterial masses, particularly the protected surfaces in the proximal spaces, are capable of and do plant infection in the tissues contiguous to them.

A further evidence of how readily this may occur is shown by a series of recent experiments with oxygen under com- 
pression which was discharged into the gum crevice from a blunt needle, not thrusting the needle deep into the crevice, but only half way toward the bottom. The oxygen will enter and be seen to lift the tissues back toward the palate and many times bubbling out of the tissues from the gum margin of a tooth a half or three-quarters of an inch removed from the point of entrance. This shows the extreme looseness of attachment of the peridental membrane and the ease of its infection. If pyorrhœa obtains for some time, say long enough to produce an average depth of ulcerating surface of a quarter of an inch about each of the teeth, we then have an ulcerating surface of seven and one-half square inches. If the average depth of pocket was only one-eighth of an inch, we have an ulcer equivalent to three and one-fourth square inches. Compare this ulcerating surface infected with all sorts of organisms to the greatest possibility of the tonsils with eight to sixteen crypts in each, and you have some idea of the relative im. portance of the dental tract in the planting of general infection.

Ulrich (4) in his paper entitled "Some Medical Aspects of Dental Disease" teaches that dental abscesses originate in the blood stream but does not tell us how the infection enters the blood claiming that the lack of vital pulp is the determining factor in the locating of abscess. As a matter of fact, hundreds of pulpless teeth are in use that are not abscessed. It is needless to state that septic root canals are responsible for many dental abscesses and it is true that modern methods have made possible the safe retention of such teeth where the individual is otherwise in good health, but on account of the exact technic to gain and maintain asepsis in such teeth, they should always be kept under surveillance by radiographic methods. Our own conclusions and belief regarding the infections that occur in the dental tract are that they usually enter by and thru the gum crevice, venæ, perivascular lymph-spaces and root-canals when opened by ulceration, decay, or careless operative procedure.

Two years ago the scientific foundation and research commission of the National Dental Association placed in our hands a sum of money $(\$ 2,000$ per year), which we determined to use to gather evidence of the relationships that mouth infection bear to metastatic in-

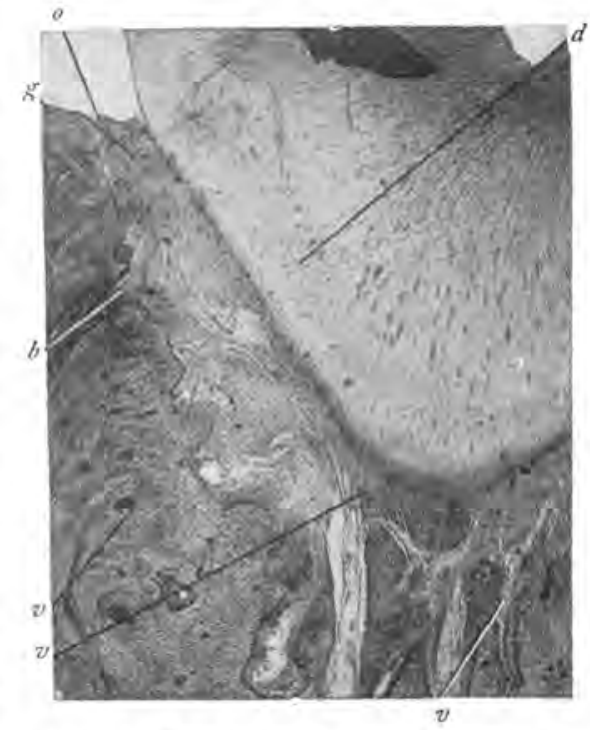

Fig. 6. Showing vense extending almost to the gingival crevice and leading into the peridental membrane. g, Gum edge, o, opening into vessels of peridental membrane, d, dentine, $b$, bone, $v$, network of vessels.

fection of other parts of the body. This research has been carried on in the laboratories of the school of medicine and has been assisted during the past year by an additional grant of funds from the research department of the graduate school. The laboratory procedures have been carried forward by Doctor Henrici of the school of medicine. Our endeavor has been to approve or disapprove, as the case might be, the clinical evidence tending to connect infections about the teeth with distant secondary infections 
of other parts of the body. To that end, we have used bacterial cultures obtained from both pyorrhœa pockets and apical muscle and endocardium, as illustrated by the three accompanying photographs. Figure 9 shows chronic myocarditis in

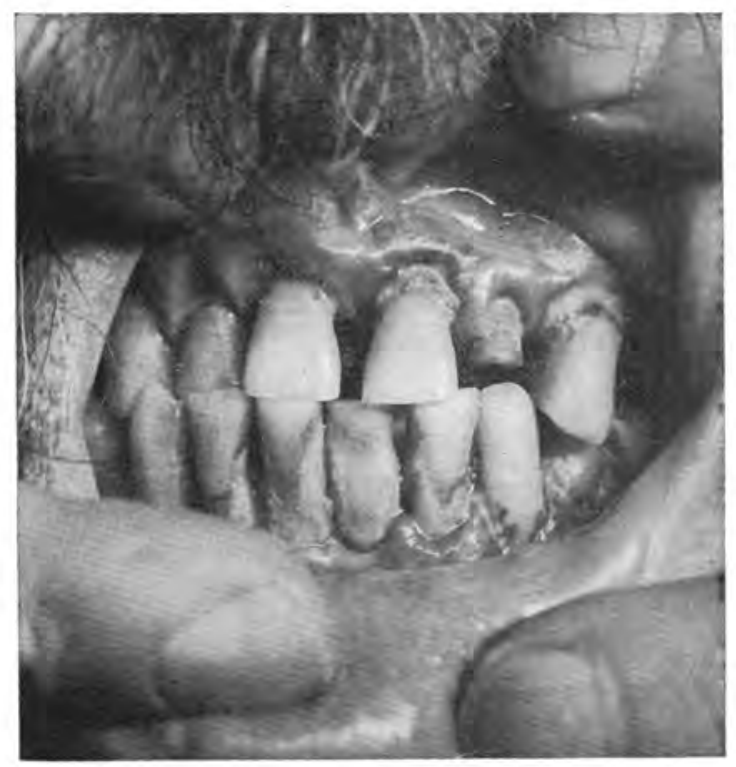

Fig. 7. Showing calculus on the tooth's neck and pus flowing from well-marked pyorrhca pockets in the mouth of a man who now has a multiple arthritis.

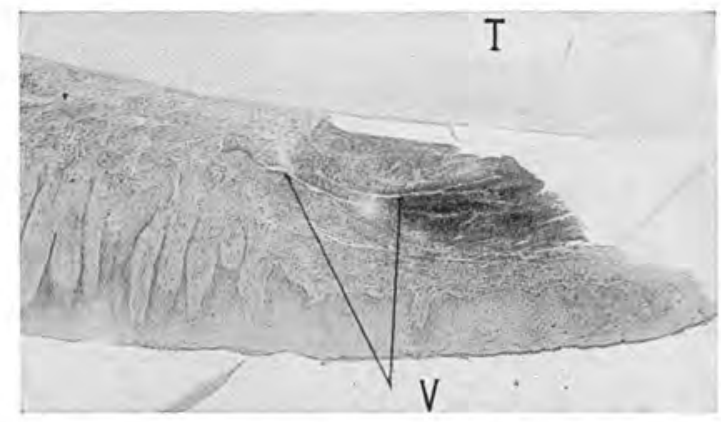

Fig. 8. Showing human pyorrhca pocket. Note the great mass of plasma cells on the ulcerating surface of the pocket. T, tooth, V, vessel.

abscesses of individuals suffering secondary infection. From our first series of cases resident in the university hospital we were able to produce lesions of heart- the heart-muscle of a rabbit which died sixteen days after an injection of streptococci from Case 55. The section shows an area of fibrosis with several giant 


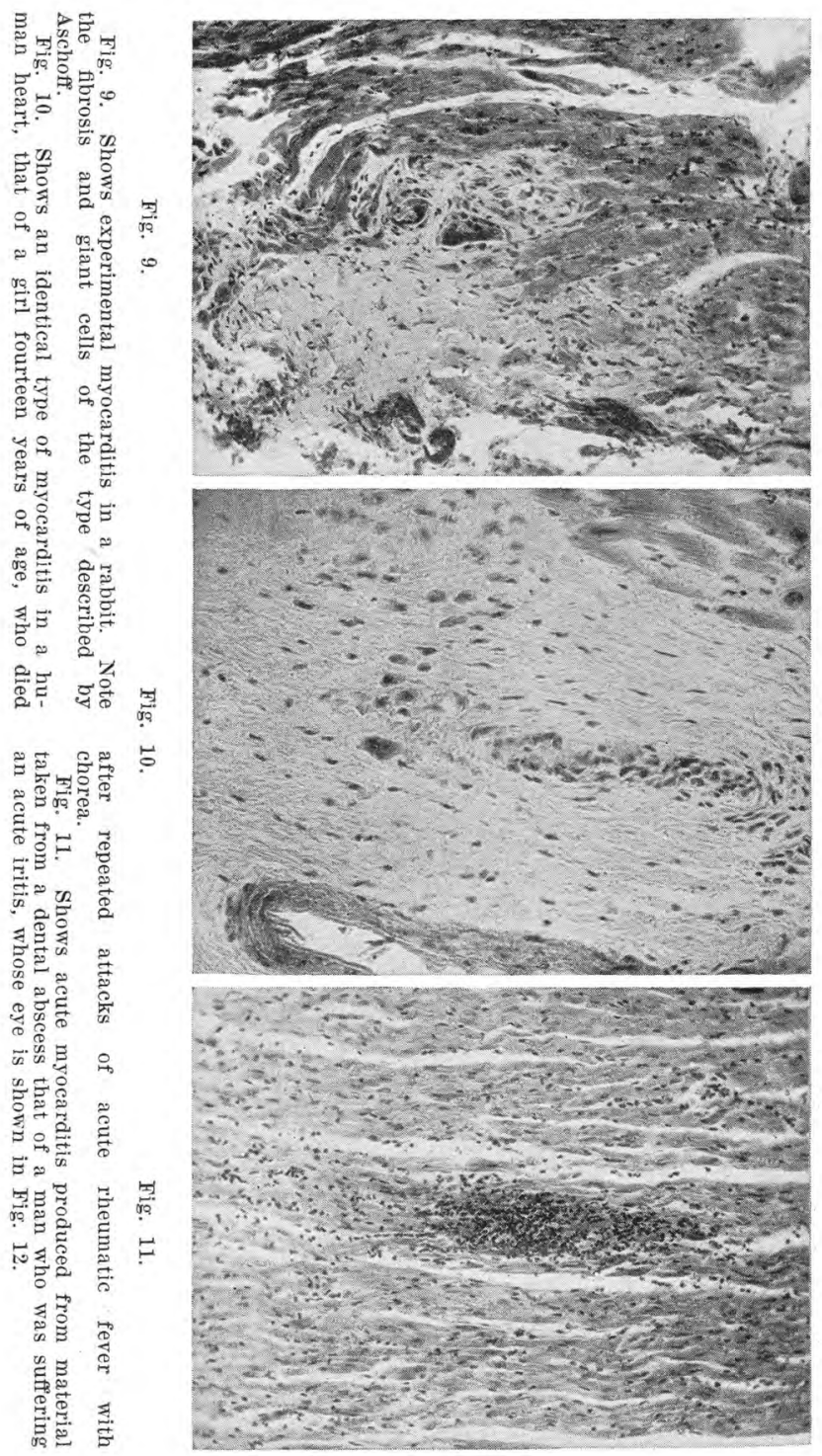


cells. This is myocarditis of the type described by Aschoff, generally considered to be specifically rheumatic in nature (Fig. 10.) found as you note. The result of treatment in this case was quite satisfactory.

Figure 11 shows an area of acute infection involving seven or eight heart-musele fibers in the heart of a rabbit which died forty-eight hours

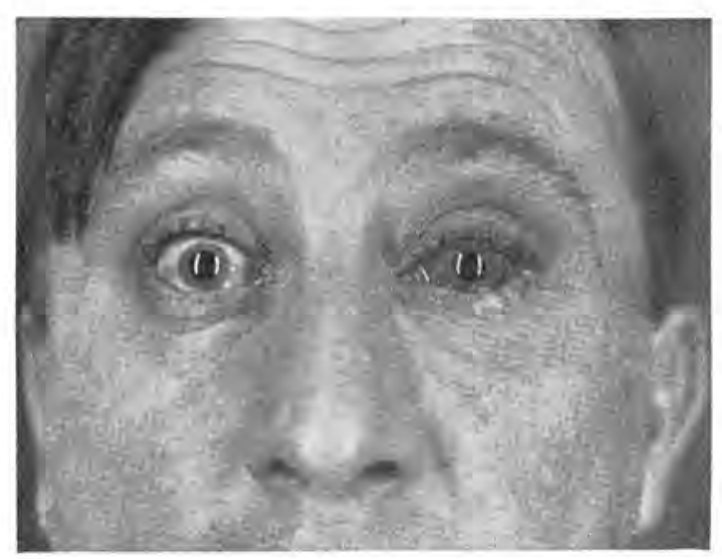

Fig. 12. Shows eyes of patient with severe iritis due to a dental abscess.

Case 55, from which we obtained the culture which produced the experimental myocarditis shown in Fig. 9, was that of a married woman of forty years of age, of German descent, by occupation a housewife, weight 150 pounds, of good habits, with no trace of famillal of veneral dis-

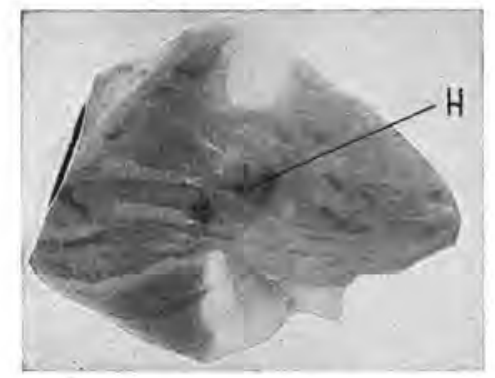

Fig. 13. Note hæmorrhage at the base of Pupllary muscles, H.

ease. When she came under our care, January 18, 1914, she had pyorrhea alveolaris, congestion of the lung bases, cardiac hypertrophy and dilatation, acute hypertrophy and dilatation, mitral incompetency and stenosis, acute aribritis, with swollen joints. The culture material was obtained from pyorrhœa pockets and extracted roots. Its effect on the heart, muscle of a rabbit was pro- after an injection of streptococci obtained from Case 60 , that of a man who was suffering an acute Iritis evidently the result of a dental abscess involving the left antrum. The iris presented posterior synechia and a marked congestion accompanied by great pain (Fig. 12). Extraction of the tooth and curettement of the sockets resulted in a rapid reduction in the inflammation of the eye and the material obtained from the tooth socket developed not only the acute inflammation shown in this picture but also a hremorrhage into the mitral cusp of the rabbit's heart shown in Fig. 13. Here we have ehronic infection of the heart-muscle with repair by scar-tissue, acute focal infection of the heart-muscle, and a hæmorrhage under the endocardium produced by the streptococeus viridans from this single source, a dental abscess.

We have since produced many such lesions with the streptococcus ordinarily found in the saliva and I will show next a section of heart-muscle in a rabbit which has received an injection of streptococci obtained not from a lesion but from saliva (Fig. 14. Note destruction of muscle-fibers).

Besides lesions of the heart-muscle, lesions of the heart valves are most commonly associated with rheumatism. The relationship of the streptococcus viri- 
dans to endocarditis has been produced in rabbits by inoculation with streptococci repeatedly, especially by Poynton and Payne and by Rosenow. Figure 15 shows vegetations on the mitral value of a patient in our series who had multiple dental abscesses. Figure 16 shows vegtative endocarditis in a rabbit experimentally produced by inoculation with streptococei obtained from a dental abscess.

Lesions of the blood-vessels accompanying rheumatism were noted in 1828 on, the patient developed a simllar lesion in the left arm.

"Much other material may be found bearing on this same question of vaseular lesions from Leger (6) and Hanot (7) who deseribed rheumatic aoritis, whlle Rabe (8) has studied rheumatic disease in the coronary artery. The latter described two princlpal lesions, one consisting of a proliferating endarteritis, the other of a diffuse mesarteritis. It is probable that the other peripheral arteries react in a manner similar to but milder than in the coronary arteries (9),"

We have made the above citations and show the following arterial lesion pictures to suggest the fallacy of the old

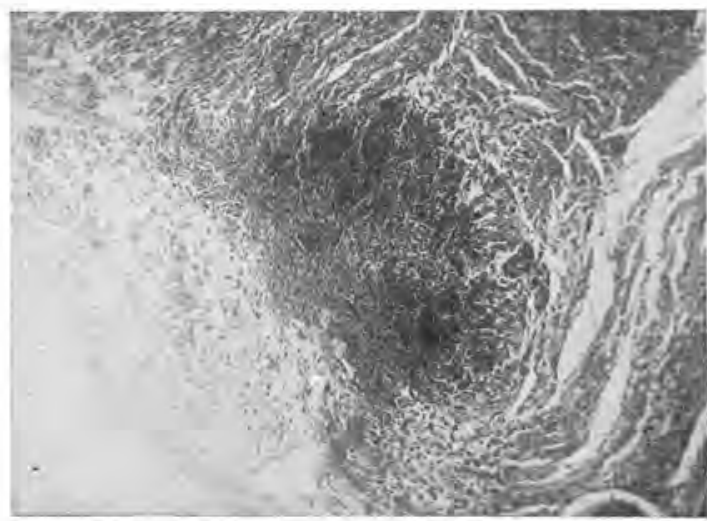

Fig. 14. Heart-musele fibers destroyed by salivary streptococcus.

by Trousseau, ${ }^{1}$ and also by Hanot, ${ }^{2}$ who supported his observations by autopsy.

\footnotetext{
"Roche and Burnand (5) reported the case of a man, age 30 , who had long suffered from rheumatism. His first attack had occurred seventeen years previously and since then he had suffered recurrent attacks, in each of which the heart was more or less involved. Recently, his heart falled to compensate for the severe lesions of the mitral and aortic valves. When seen by the author, he was cyanosed and showed œdema of the lower extremeties. He had continuous fever of moderate degree. After some weeks his temperature suddenly went up, and he complained of pain in the left arm, which continued to increase. In three days the radial pulse disappeared, gradually a small radial pulse was again obtained. After some weeks a mass appeared close to the upper humerus which was quite painful to touch. Later
}

${ }^{1}$ Archiv gén.. de méd., 1828, xvi, 499.

"Presse méd., Par., 1896, 1, p. 649. established belief that all aortic arch lesions are specific when it is quite possible that some may also be of streptococcal origin. The relationship of rheumatism to diseases of the aortic arch has been recently studied by Klotz (9), who finds constantly a characteristic lesion of the adventitia. Such a lesion is shown in Fig. 17, which is a section of the aorta of the girl whose myocardium is shown in Fig. 10. The section shows submiliary foci of infiltration about the vasovasorum of the adventitia. Figure 18 shows a similar but more extensive lesion in the adventitia of the aorta of a rabbit inoculated with streptococcus viridans from a dental abscess.

In a recent series of thirty animals in- 
oculated with ordinary salivary streptococci by us, we have found a number of animals whose joints are filled with puscontaining streptococcus viridans. They to give greater attention to closing the door to this infection by treatment directed toward the prevention and cure of pyorrhoa and dental abscess and the

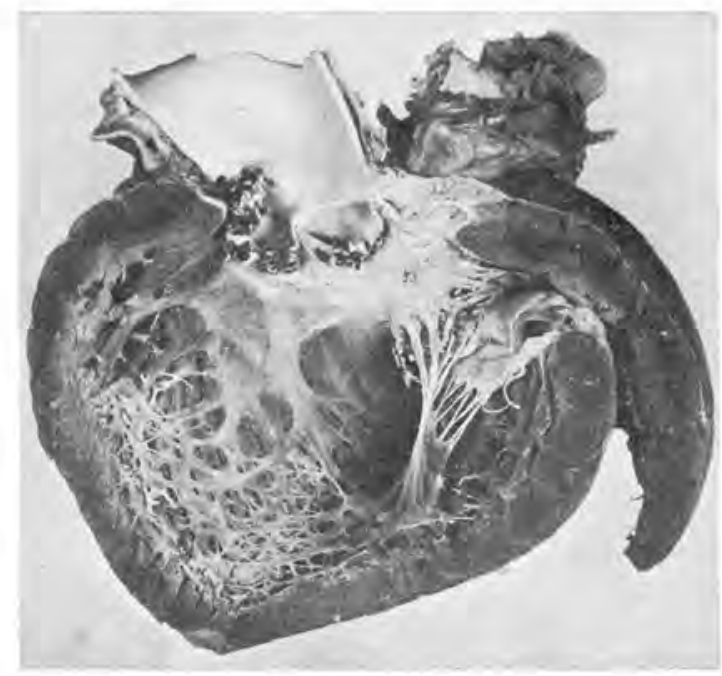

Fig. 15. Shows vegetations on the mitral valve of a patient in our series who had multiple dental abscesses.

also exhibit heart-muscle infection, and well-formed vegetations on heart-valves, focal infections of the kidneys as well as diffused kidney infection. In ordinary

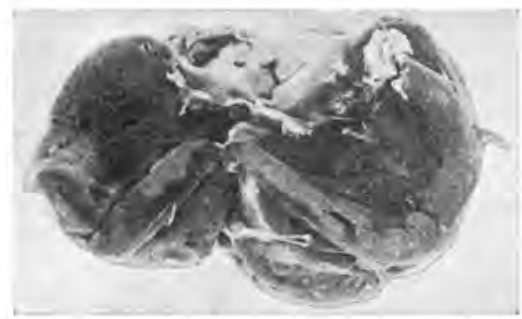

Fig. 16. Vegetative endocarditis in a rabbit experimentally produced by inoculation with streptococei obtained from a dental abscess.

salivary streptococci will produce these lesions just as will streptococci taken from the dental abscess or the pyorrhœa pocket, it would seem well worth while maintenance of health in the whole dental tract.

In addition to the lesions already shown which involve heart-muscle, endocardium, and vessels, we desire to show you a picture of a focal and diffused infection of the kidneys produced from material taken from a dental abscess from Case 59, which produced two types of streptococci; one growing gray on blood agar, the other growing green. Both strains were isolated in pure culture. In massive doses, broth culture produced death in twenty-four hours; in smaller doses $(8 \mathrm{~cm}$.), death occurred in forty-eight hours. The green strain produced hæmorrhage into the mitral cusp of the rabbit's heart, the other strain produced minute multiple abscesses thruout the kidney cortex. The streptococci were reobtained in pure culture from the blood of both rabbits, and, after 

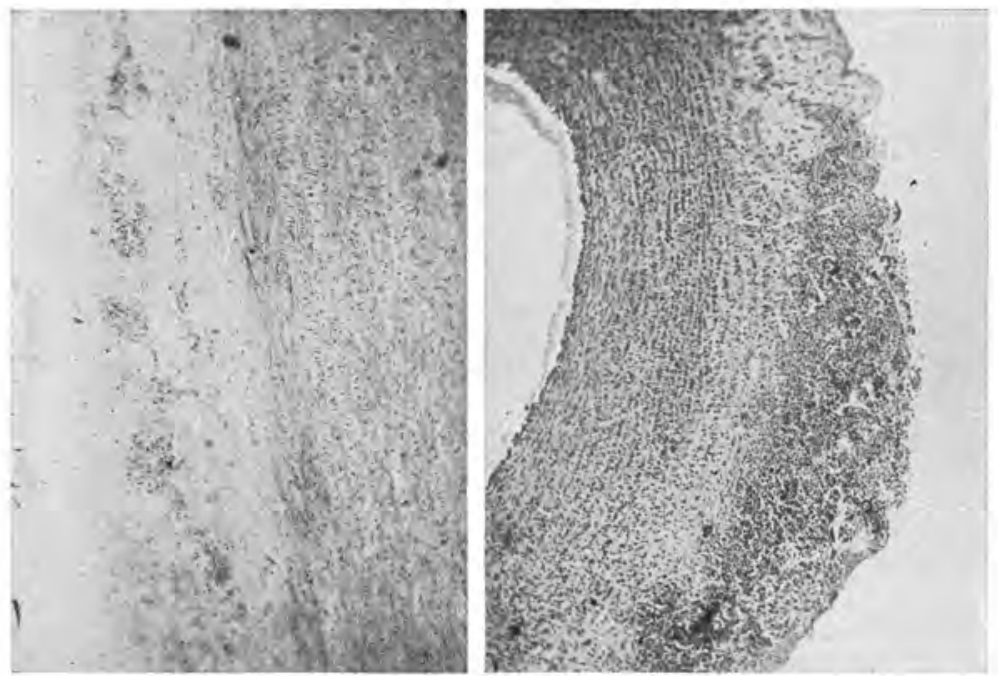

Fig. 17 (at left). Seetion of the aorta of the girl whose nyyocardium is shown in Fig. 10. Fig. 18. A similar but more extensive lesion in the adventitia of the aorta of a rabbit inoculated with streptococcus viridans from a dental abscess.
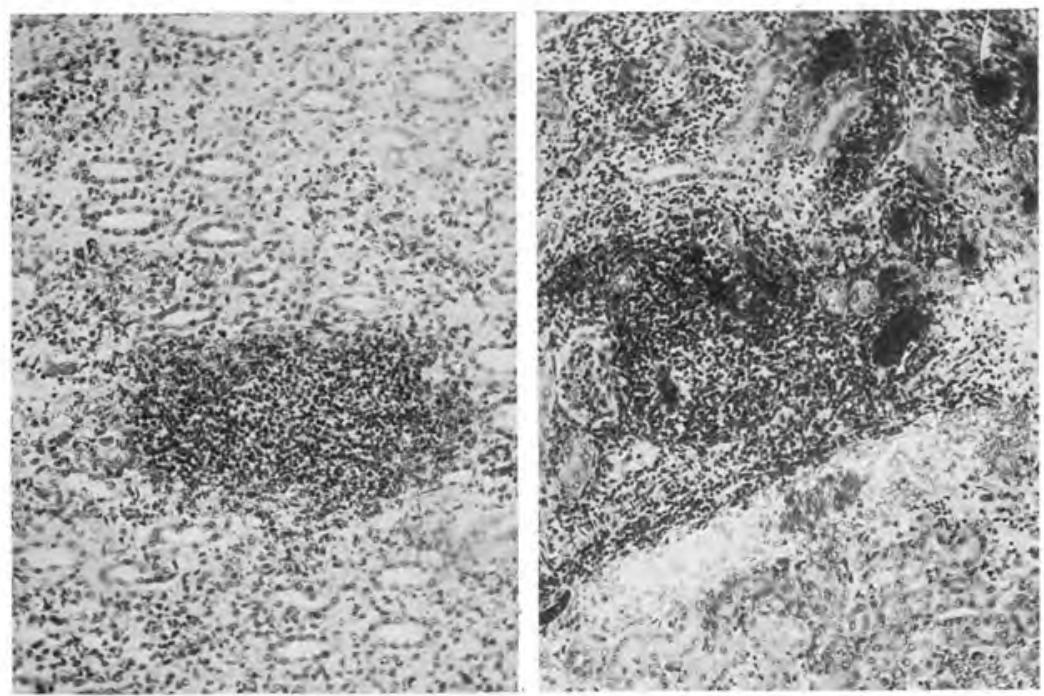

Fig. 19 (at left). Multiple abscesses in the cortex of a rabbit's kidney induced by material originally obtained from a dental abscess in the mouth of a man whose hands and feet are shown in Figs. 21 and 22.

Fig. 20. Bacterial emboli and the capillaries of the eortex have surrounding areas of inflammatory infiltration which show both pus-cells and lymphocytes. 
twenty-four hours' incubation, were injected into two new rabbits in $5 \mathrm{ccm}$. doses. Both of these rabbits died within 48 hours. The autopsy revealed no lesions save for a large number of miliary abscesses in the cortex of the kidneys (Fig. 19). The streptococci were again recovered in pure culture from the heart's blood and from the kidneys, and these are the kidneys shown in microscopic section (Fig. 20). They show bacterial emboli, and the capillaries of the cortex have surrounding the first culture was obtained is forty years of age and has suffered from arthritis deformans for twenty years. This has resulted in the partial disarticulation of his phalangeal joints of both hands and feet as shown by the accompanying pietures (Figs, 21 and 22.)

While we have not done systematic research with the other constant bacterial inhabitants of the mouth we have dealt practically with many cases of secondary infection in which the primary lesion commenced in the dental arches and resulted in multiple abscesses in different parts of the body.

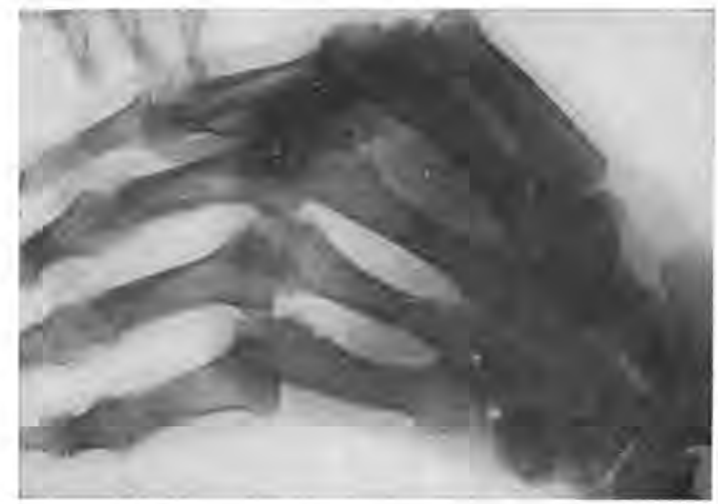

Fig. 21. Hands of a man from whose dental abscesses we took the material originally to produce the lesions in Figs. 19 and 20.

areas of inflammatory infiltration which exhibit both polymorphonuclears and lymphocytes. There was a pronounced necrosis in the breast muscles of a pigeon inoculated with this strain, which died within twenty-four hours. Our comment on this strain is that we have apparently an organism belonging to the streptococcus viridans class possessing a high degree of virulence which is indicated by the rapidity with which it causes death in animals and by the fact that it calls out pus-cells in the infecte1 animals. We note also that this strain shows a marked affinity for kidneys as there were no joint lesions and no heart lesions except a valve hæmorrhage.

Case 59. The patient from whose dental abscess
A recent ease, that of a youth of sixteen, developed an acute primary abscess in a lower central. This resulted in a general pyæmia producIng abscesses in different parts of the body, the most pronounced of which were in the gluteal muscles. The primary effeet of the infection in the jaws was to destroy the whole body of the lower jaw from the ramus forward, the whole body of which has been removed gradually, retaining only enough of it to act as a split while the new body has developed.

Cases of this type are fairly common particularly in the mouths of people who are careless in the care of their teeth.

A second of the acute staphylococcal type was that of a physician with a primary abscess about a lower molar which resulted in the loss of one inch and a half of bone and the destruction of the facial nerve on the right side. 
A third ease of similar nature, a primary staphylococeal abscess about the lower third molar in the mouth of a young Swedish girl, resulted in the loss of the angle of the jaw and secondary metastatic abscesses in other parts of the body.

In addition to these cases we have on record the experience gained in the care of six individuals who died as a result of primary mouth infections spreading to other parts of the body in which cases autopsy disclosed only the mouth as a primary focus. One of these deaths was due to a fusiform bacillus infection originating around two central incisors. The been the host of this stinking abscess for some five years prior to its removal. Surely the responsibilites of those who have to do with the prevention of the development and growth of streptococci in the mouths of people are of a grave nature indeed. Bacteria grow on the mucous membranes but sparsely as compared to the enormous numbers, particularly of streptococci, which grow on tooth surfaces and in gum crevices, and the further fact that we have a direct continuity of the tooth's surface with

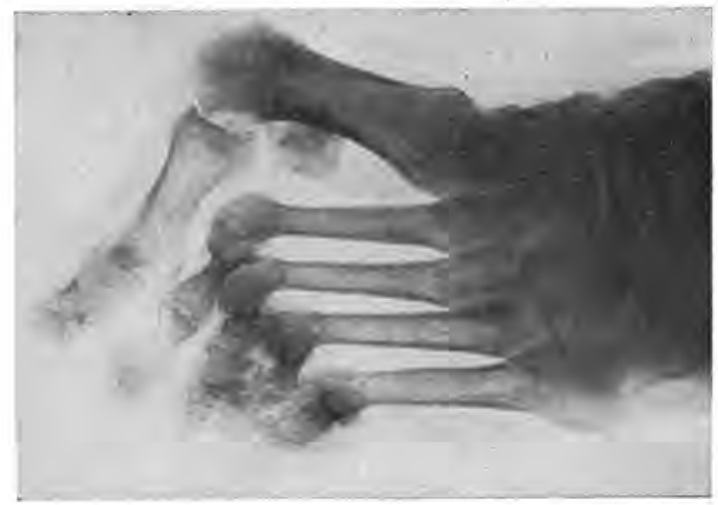

Fig. 22. Feet of man from whose dental abscesses material was taken to produce the lesions in Figs. 19 and 20.

primary culture and smear disclosed normous numbers of fusiform bacilli in this slough and a blood culture taken by Doctor Larson disclosed a general fusiform bacillus infection in the blood stream. Our experience with the damaging effects of the diplococcus as a mouth inhabitant is limited to one case in which the primary infection around a bicuspid yielded the diplococcus pneumonia in large numbers. Removal was coincident with a pneumonia involving the lower lobes of each lung. The patient made an uneventful recovery from the pneumonia two years ago last winter only to die of a second pneumonia January, 1914. The infected socket had the imperfectly protected gingival crevice makes the tooth's surface, when loaded with organisms, a factor worthy of the serious consideration of those who deal with human life.

\section{REFERENCES}

1. Research on Rheumatism, p. 213.

2. J. Allied Soc., 1915, September.

3. Ulrich Dental Review, 1914.

4. Dental Review, 1914.

5. Roche and Burnand. Semaine méd., 1908, xxvili, 145 .

6. Leger. Thése de doct., Paris, 1877.

7. Hanot. Presse méd., Par., 1896, I, 649.

8. Rabe, Presse méd., Par., 1902, 11, 927.

9. Quoted from Klotz. J. Path. \& Bacteriol, 1913, xvili.

10. Klotz. J. of Path. \& Bacteriol., 1913, xviil. 